\title{
Analysis of Land Cover and Landscape Pattern Change in Beijing-Tianjin-Hebei Region Based on Globeland30 Data
}

\author{
Yimeng Shi ${ }^{1}$, Hongli Song ${ }^{1,2,3^{*}}$, Ming Shang ${ }^{1,3}$, Mingchao Shao${ }^{1}$, Haimei Lei ${ }^{1}$ \\ ${ }^{1}$ College of Geosciences and Engineering, Hebei University of Engineering, Handan, China \\ ${ }^{2}$ Hebei Coal Resources Comprehensive Development and Utilization Collaborative Innovation Center, Handan, China \\ ${ }^{3}$ Handan Key Laboratory of Natural Resources Spatial Information, Handan, China \\ Email: ^songholi2003@163.com
}

How to cite this paper: Shi, Y.M., Song, H.L., Shang, M., Shao, M.C. and Lei, H.M. (2020) Analysis of Land Cover and Landscape Pattern Change in Beijing-Tianjin-Hebei Region Based on Globeland30 Data. Journal of Geographic Information System, 12, 241-255. https://doi.org/10.4236/jgis.2020.123015

Received: April 5, 2020

Accepted: June 26, 2020

Published: June 29, 2020

Copyright (๑) 2020 by author(s) and Scientific Research Publishing Inc. This work is licensed under the Creative Commons Attribution International License (CC BY 4.0).

http://creativecommons.org/licenses/by/4.0/

\begin{abstract}
With the rapid economic development and urbanization process in Beijing-Tianjin-Hebei region, land use and landscape pattern have been changed. In order to reveal the temporal and spatial changes and provide scientific basis for the local land use planning and landscape pattern optimization made by government, based on the classification results of Globeland 30 land cover data in 2000 and 2010, this paper quantitatively analyzed the land use transfer status and the dynamic change of landscape pattern in Beijing-Tianjin-Hebei by adopting the method of land use transfer matrix and landscape index. The results show that the land use and landscape patterns in Beijing-Tianjin-Hebei have been changed significantly from 2000 to 2010 . Overall, land use in Beijing-Tianjin-Hebei region has been changed greatly, which shows that the cultivated land area has been decreased by $3721.67 \mathrm{~km}^{2}$, while the artificial surface area and grassland area have increased by 2721.29 $\mathrm{km}^{2}$ and $657.09 \mathrm{~km}^{2}$, respectively. From the six partitions of Beijing-Tianjin-Hebei, it can be seen that the subareas with significant changes are Sand Control Farmland Protection Zone in Yellow River Flood Plain, Water Conservation Area for Sand Control in Mountain and Hilly Areas of Northwest Taihang Mountains, and Human Settlement Environment Maintenance and Farmland Protection Zone of Beijing-Tianjin-Hebei Urban Agglomeration. The arable land area of these three zones has decreased 572.77 $\mathrm{km}^{2}, 1553.94 \mathrm{~km}^{2}$ and $1359.53 \mathrm{~km}^{2}$, respectively. From the perspective of landscape pattern change, patch density and fragmentation degree in the southeast and northwest of Beijing-Tianjin-Hebei region increase; and the dominant patches in the southeast of Beijing-Tianjin-Hebei region have formed a good connectivity; the whole Beijing-Tianjin-Hebei region shows
\end{abstract}


irregular shape and discontinuous enhancement of landscape types, the landscape patch types increase and enrich, and the dominance shows a downward trend.

\section{Keywords}

Land Use Transfer Matrix, Landscape Pattern, Landscape Index, Globeland30

\section{Introduction}

Land use/land cover change (LUCC), as the main manifestation of human activities that significantly change the Earth's environmental system, is a hot and frontier area of global environmental change research [1] [2] [3] [4]. With the acceleration of economic development, population growth and urbanization, the role of human beings on the earth's surface has been strengthened, and the land use and landscape patterns on the earth's surface have been changing constantly [5]. Therefore, the analysis of land use and landscape pattern between regions plays a key role in the sustainable development of the region [6]. With the continuous progress of remote sensing technology, especially the emergence and renewal of land cover products [7]-[13], it provides an effective means of detection and data sources for the study of land use change at global and regional scales. In response to the above problems, scholars at home and abroad have carried out a lot of research and achieved fruitful results, such as Fan et al. [14] using land use dynamics model, land use transfer matrix and mobile window landscape index to analyze the spatial and temporal change process of land use landscape pattern in Shanghai from 1995 to 2015; Wang et al. [15] selected the upper reaches of Huaihe River to study the impact mechanism of land use and landscape pattern evolution on ESV. Zhang et al. [16] supported by remote sensing and GIS technology, used land use conversion matrix to analyze the land use pattern of Zhungeer Banner in two invariable years, and combined with soil erosion data to analyze the change of soil and water loss in the region. Lamine et al. [17] selected relevant indexes in FRAGSTATS to analyze the relationship between land use/land cover change and landscape fragmentation in the Mediterranean region. Most of these land use status and landscape pattern studies are based on cities or small areas as research areas, and few are evaluated from a whole region. Therefore, this paper selects the Beijing-Tianjin-Hebei region as the research area, and adopts the two methods of land use conversion matrix and landscape index to analyze the changes in land use status on a larger spatial scale.

In 2014, the National Basic Geographic Information Center launched GlobeLand 30, a global $30 \mathrm{~m}$ resolution remote sensing cartographic data product for surface coverage includes products of 2000 and 2010. At present, the Chinese government has donated and opened up to the United Nations to share the data product [18] [19]. Due to the short time of occurrence of GlobeLand30 data, 
there are few studies on this high-resolution land cover data, most of which are aimed at the accuracy evaluation of the land cover products at global or national scales and land cover change [20] [21] [22] [23]. However, little is known about the landscape pattern analysis at regional scales using GlobeLand30 data. Based on these, this paper adopts the method of land use transfer matrix and landscape index to analyze the Beijing-Tianjin-Hebei region by using two-period data of Globeland 30 and reflects the transfer situation and structural feature of land use types in the region from 2000 to 2010 in a quantitative and intuitive way, so as to provide a reference for analyzing the law of land use transfer in the region and reveal the characteristics of landscape pattern change in Beijing-Tianjin-Hebei.

\section{Materials and Methods}

\subsection{Overview of the Study Area}

The Beijing-Tianjin-Hebei region is located at $113^{\circ} 04^{\prime} \mathrm{E}-119^{\circ} 53^{\prime} \mathrm{E}$ longitude and $36^{\circ} 01^{\prime} \mathrm{N}-42^{\circ} 37^{\prime} \mathrm{N}$ latitude, east of Bohai Sea, west of Taihang Mountains, north of Yanshan Mountain, high in the northwest and low in the southeast, with an area of about 217 thousand $\mathrm{km}^{2}$, mainly including Beijing, Tianjin and Hebei Province. [24] Based on the comprehensive analysis of the existing literature [25] [26], this paper divides the Beijing-Tianjin-Hebei area into six parts, they are Sand Control Farmland Protection Zone in Yellow River Flood Plain, Water Conservation Area for Sand Control in Mountain and Hilly Areas of Northwest Taihang Mountains, Water Conservation and Soil Conservation Area in Mountain and Hilly Areas of Eastern Taihang Mountains, Ecological Maintenance Zone of Bohai Bay in Tianjin-Hebei-Shandong, Human Settlement Environment Maintenance and Farmland Protection Zone of Beijing-Tianjin-Hebei Urban Agglomeration, Ecological Maintenance Area of Water Conservation in Hilly Area of Yanshan Mountain, as shown in Figure 1.

\subsection{Data Sources and Processing}

The surface coverage data used in this paper is Globeland30 data with $30 \mathrm{~m}$ resolution of 2000 and 2010. Supported by 863 national key projects, the product was developed by the National Basic Geographic Information Center in conjunction with 18 units, such as Beijing Normal University, Tsinghua University and the Institute of Remote Sensing application (IRSA) of Chinese Academy of Sciences [27] [28], using WGS84 coordinate system and UTM projection. Its classified images are mainly multi-spectral images with $30 \mathrm{~m}$ resolution, including multispectral images of China Environmental Disaster Reduction Satellite (HJ-1), Beijing 1 (BJ-1) and Landsat TM5, ETM+ [18]. Ground cover can be divided into 10 categories: cultivated land, forest, grassland, shrub land, wetland, water body, artificial surface, bare land, glacier and permanent snow cover, tundra. The overall accuracy in 2000 is $85.8 \%$, the Kappa coefficient is 0.79 , the overall accuracy in 2010 is $86.9 \%$, and the Kappa coefficient is 0.81 [28]. The 


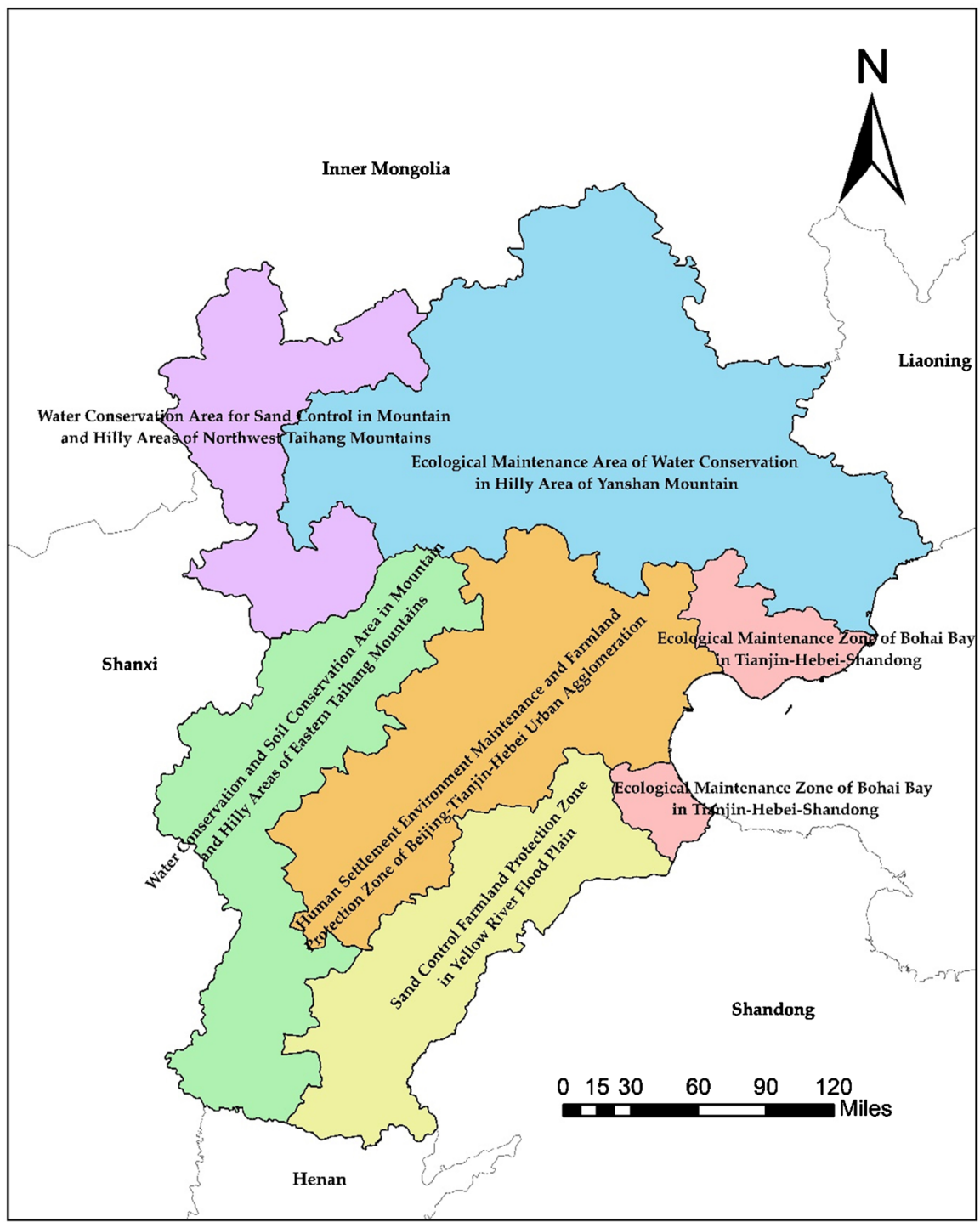

Figure 1. Location of the study area.

Globeland30 data used in this paper is downloaded from the National Basic Geographic Information Center, which website is http://ngcc.sbsm.gov.cn/.

In GIS software, the data in the study area is obtained by projection transformation, image mosaic, research area clipping and so on. Because shrub land and bare land occupy less area in Beijing-Tianjin-Hebei area, and there are no glaciers, permanent snow and tundra areas in the study area, it is necessary to reclassify these data and eventually merge them into seven types of land cover, namely cultivated land, forest, grassland, wetland, water body, artificial surface and others.

\subsection{Research Methods}

\subsubsection{Land Use Transfer Matrix}

The transfer matrix of land use reflects the dynamic process information of the transformation between different land types of area at the beginning and the end 
of a certain period in a certain region. It includes not only the static data of different types of area at a certain time point in a certain region, but also the more abundant information of different types of area transfer at the beginning and at the end of the period. The general form of land use transfer matrix is [29] [30]:

$$
S_{i j}=\left[\begin{array}{cccc}
S_{11} & S_{12} & \cdots & S_{1 n} \\
S_{21} & S_{22} & \cdots & S_{2 n} \\
\cdots & \cdots & \cdots & \cdots \\
S_{n 1} & S_{n 2} & \cdots & S_{n n}
\end{array}\right]
$$

where $S$ represents area; $n$ is the number of land use types before and after transfer; $i, j(i, j=1,2, \cdots n)$ represents the land use types before and after the transfer, respectively; $S_{i j}$ denotes the area of the class $i$ before the transfer to the class $\mathrm{j}$ after the transfer.

\subsubsection{Landscape Index}

Landscape index refers to quantitative indicators which can highly condense the information of landscape pattern and reflect some characteristics of landscape structural composition and spatial allocation [31]. Due to the high correlation between landscape pattern indexes, the representative, easy to quantify and relatively sensitive indicators should be selected according to the characteristics of the study area, geographical environmental factors and research needs, combined with the ecological meaning of each indicator. [32] [33] The landscape pattern can be analyzed from three different levels: patch level, patch class level and landscape level. Based on the existing literature [34], this paper intends to use landscape level index to analyze the fragmentation and spatial heterogeneity of the Beijing-Tianjin-Hebei region. Patch Density (PD), Edge Density (ED), Landscape Shape Index (LSI), Contagion Index (CONTAG), Shannon Diversity Index (SHDI) and Shannon Evenness Index (SHEI) are selected to study Landscape pattern change of Beijing-Tianjin-Hebei. The formula for calculating the specific index is shown in Table 1.

\section{Results}

\subsection{Matrix Analysis of Land Use Transfer}

\subsubsection{Land Use Transfer in Beijing-Tianjin-Hebei Region}

Based on the land cover remote sensing image classification results of the two phases of GlobeLand30, and adopting the land use transfer matrix method, the GIS tools were used to generate the transfer matrix between land use types in Beijing-Tianjin-Hebei area, as shown in Table 2. It can be seen from Table 2 that from 2000 to 2010, land transfer in the entire Beijing-Tianjin-Hebei region mainly occurred between cultivated land, artificial surface and grassland, while the changes between forests, wetlands and water bodies were smaller, and their changes were $349.72 \mathrm{~km}^{2}, 175.23 \mathrm{~km}^{2},-189.94 \mathrm{~km}^{2}$. During the ten-year period, the total area of arable land decreased by $3721.67 \mathrm{~km}^{2}$, and its transfer-out area was $7813.11 \mathrm{~km}^{2}$, of which the area converted into grassland and artificial surface 
Table 1. The formula of landscape metrics.

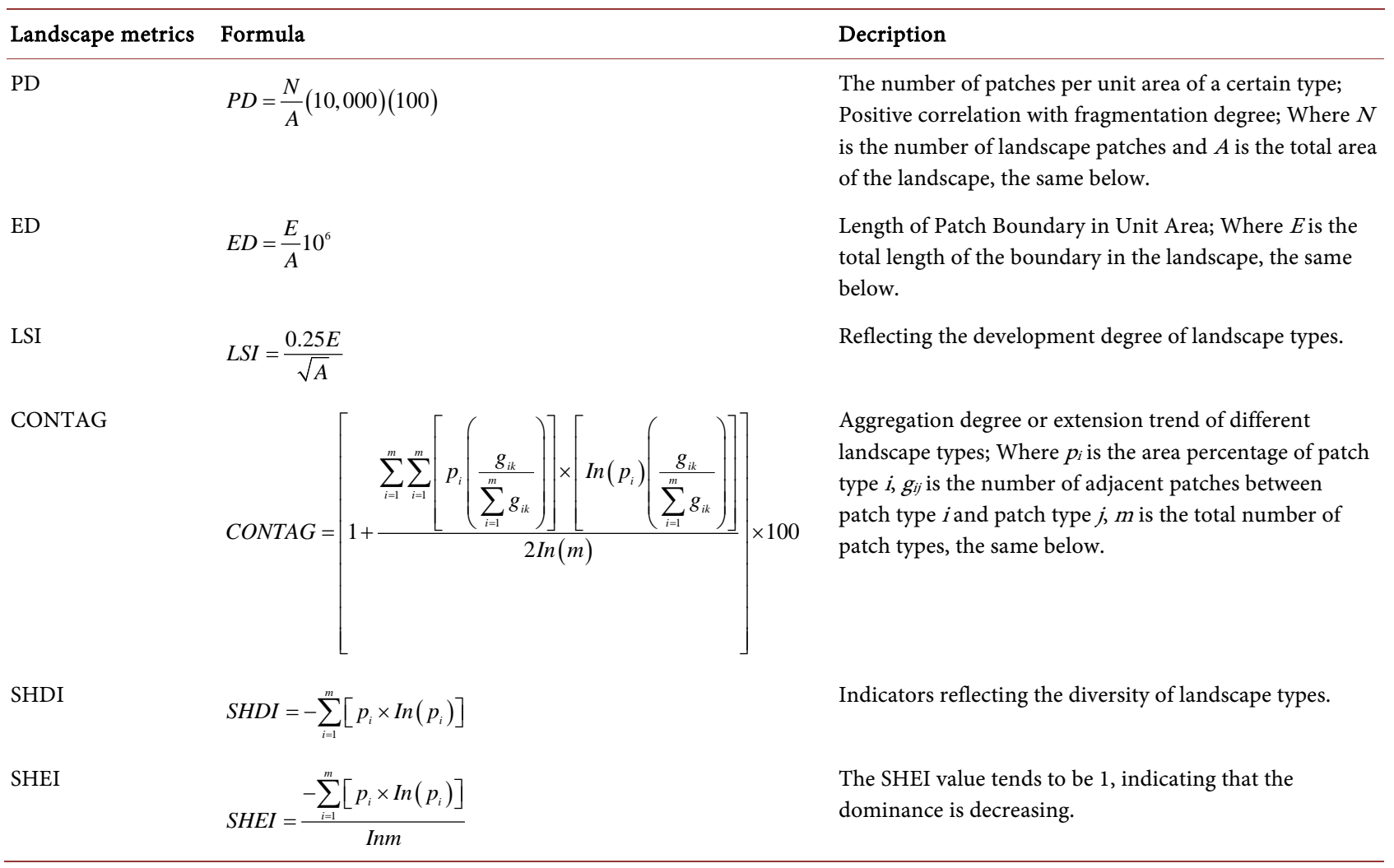

Table 2. Land use transfer matrix in Beijing-Tianjin-Hebei region

\begin{tabular}{|c|c|c|c|c|c|c|c|c|c|}
\hline \multirow{2}{*}{$\begin{array}{l}\text { Land use in } \\
2000 / \mathrm{km}^{2}\end{array}$} & \multicolumn{8}{|c|}{ Land use in $2010 / \mathrm{km}^{2}$} & \multirow[b]{2}{*}{$\begin{array}{c}\text { Transferred-out } \\
\text { area } / \mathrm{km}^{2}\end{array}$} \\
\hline & Cultivated land & Forest & Grassland & Wetland & Water body & Artificial surface & Others & Total & \\
\hline Cultivated land & $108,487.79$ & 496.35 & 3110.37 & 97.27 & 677.26 & 3406.53 & 25.34 & $116,300.90$ & 7813.11 \\
\hline Forest & 371.82 & $36,878.17$ & 4287.55 & 3.75 & 6.18 & 55.98 & 89.43 & $41,692.88$ & 4814.71 \\
\hline Grassland & 1789.39 & 4533.26 & $30,545.55$ & 79.61 & 57.02 & 515.83 & 147.40 & $37,668.06$ & 7122.51 \\
\hline Wetland & 84.78 & 3.64 & 19.13 & 365.34 & 175.47 & 13.57 & 7.91 & 669.83 & 304.49 \\
\hline Water body & 535.83 & 60.26 & 150.56 & 274.81 & 2796.63 & 153.08 & 5.75 & 3976.91 & 1180.28 \\
\hline Artificial surface & 1300.76 & 24.13 & 58.22 & 9.85 & 45.20 & 13481.97 & 0.98 & $14,921.09$ & 1439.13 \\
\hline Others & 8.87 & 46.80 & 153.77 & 14.44 & 29.22 & 15.44 & 112.98 & 381.51 & 268.53 \\
\hline Total & $112,579.23$ & $42,042.61$ & $38,325.15$ & 845.06 & 3786.98 & 17642.39 & 389.79 & $215,611.20$ & $103,031.96$ \\
\hline $\begin{array}{c}\text { Transferred-in } \\
\text { area } / \mathrm{km}^{2}\end{array}$ & 4091.44 & 5164.43 & 7779.60 & 479.72 & 990.34 & 4160.42 & 276.81 & $99,310.29$ & $95,218.85$ \\
\hline
\end{tabular}

accounted for $39.81 \%$ and $43.60 \%$, respectively. Both the artificial surface and the grassland showed an increasing trend, with the area increasing by $2721.29 \mathrm{~km}^{2}$ and the grassland area increasing by $657.09 \mathrm{~km}^{2}$.

\subsubsection{Land Use Transfer in the Subareas of Beijing-Tianjin-Hebei}

Similarly, using the land-use transfer matrix method and the GlobeLand30 land 
cover classification images of the six districts of Beijing-Tianjin-Hebei, transfer matrices between the land-use types of the six districts were generated. In order to more intuitively display the changes in the land use types and the magnitude of the changes in each subarea from 2000 to 2010, a percentage accumulation chart was used, as shown in Figure 2. Figure 2 shows that between 2000 and 2010, the land use types of the Sand Control Farmland Protection Zone in Yellow River Flood Plain changed largely in grasslands and wetlands, and the reductions reached $15.76 \%$ and $45.84 \%$, respectively; while the cultivated land and man-made surface changed little, but because of the large proportion of the area in the district, there was still a large change in the area level, specifically the conversion between cultivated land and man-made land surface, the converted out area of cultivated land is $572.77 \mathrm{~km}^{2}$, and the area converted into artificial land is $502.86 \mathrm{~km}^{2}$, accounting for $87.79 \%$ of the total transfer area of cultivated land. The transfer area from artificial surface to cultivated land accounts for $98.02 \%$ of the former's transferred area.

The conversion of land use types mostly occurs among cultivated land, forest and grassland in Water Conservation Area for Sand Control in Mountain and Hilly Areas of Northwest Taihang Mountains. The area of cultivated land transferred out is $2070.25 \mathrm{~km}^{2}$, and the transferred in area is $516.31 \mathrm{~km}^{2}$, which reduces $1553.94 \mathrm{~km}^{2}$. The area of grassland transferred out is $825.09 \mathrm{~km}^{2}$, the transferred in area is $2167.95 \mathrm{~km}^{2}$, and the area of grassland has increased by $1342.86 \mathrm{~km}^{2}$. Among them, the area of cultivated land transferred to grassland reached $1883.89 \mathrm{~km}^{2}$, accounting $91.00 \%$ of the converted area of cultivated land. The area of grassland transferred to cultivated land and forest is 425.47 $\mathrm{km}^{2}$ and $212.58 \mathrm{~km}^{2}$, respectively, accounting for $51.57 \%$ and $25.76 \%$ of the transferred area.

From 2000 to 2010, the land use types of Water Conservation and Soil Conservation Area in Mountain and Hilly Areas of Eastern Taihang Mountains did not change much compared with other areas, and the overall change tended to be stable. The areas of cultivated land, forest, grassland, wetland, water body, artificial surface and others which have been changed are $-15.93 \mathrm{~km}^{2},-13.50 \mathrm{~km}^{2}$, $-97.74 \mathrm{~km}^{2}, 2.87 \mathrm{~km}^{2},-13.95 \mathrm{~km}^{2}, 133 \mathrm{~km}^{2}$ and $5.30 \mathrm{~km}^{2}$, respectively.

The land use types change in Ecological Maintenance Zone of Bohai Bay in Tianjin-Hebei-Shandong mainly occurs among cultivated land, wetland, water body and artificial surface. Among them, the transferred out area of cultivated land is $501.17 \mathrm{~km}^{2}$, the transferred in area is $199.42 \mathrm{~km}^{2}$, which reduces 301.75 $\mathrm{km}^{2}$, and the transferred area to wetland, water body and artificial surface is $32.39 \mathrm{~km}^{2}, 177.23 \mathrm{~km}^{2}$ and $279.90 \mathrm{~km}^{2}$. From 2000 to 2010 , the areas of wetland and man-made surface increase by $66.85 \mathrm{~km}^{2}$ and $255.63 \mathrm{~km}^{2}$, respectively.

The land use types of Human Settlement Environment Maintenance and Farmland Protection Zone of Beijing-Tianjin-Hebei Urban Agglomeration showed drastic changes in cultivated land and man-made surface. The transferred out and in area of cultivated land is $2118.41 \mathrm{~km}^{2}$ and $758.88 \mathrm{~km}^{2}$, which reduces 
(a) Land use transfer matrix of Sand Control and Farmland Protection Zone in Yellow River Flood Plain from 2000 to 2010

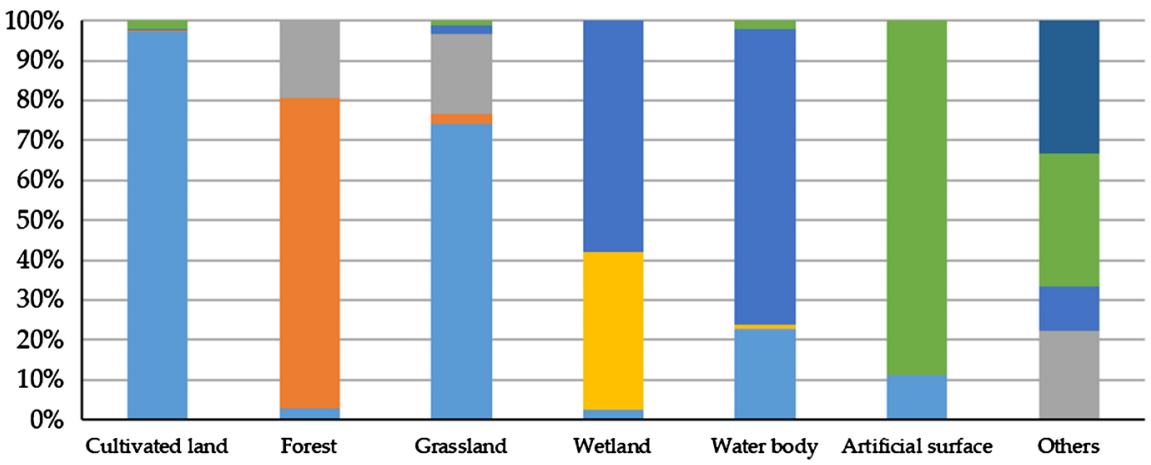

(b) Land use transfer matrix of Water Conservation Area for Sand Control in

(b) Mountain and Hilly Areas of Northwest Taihang Mountains from 2000 to 2010

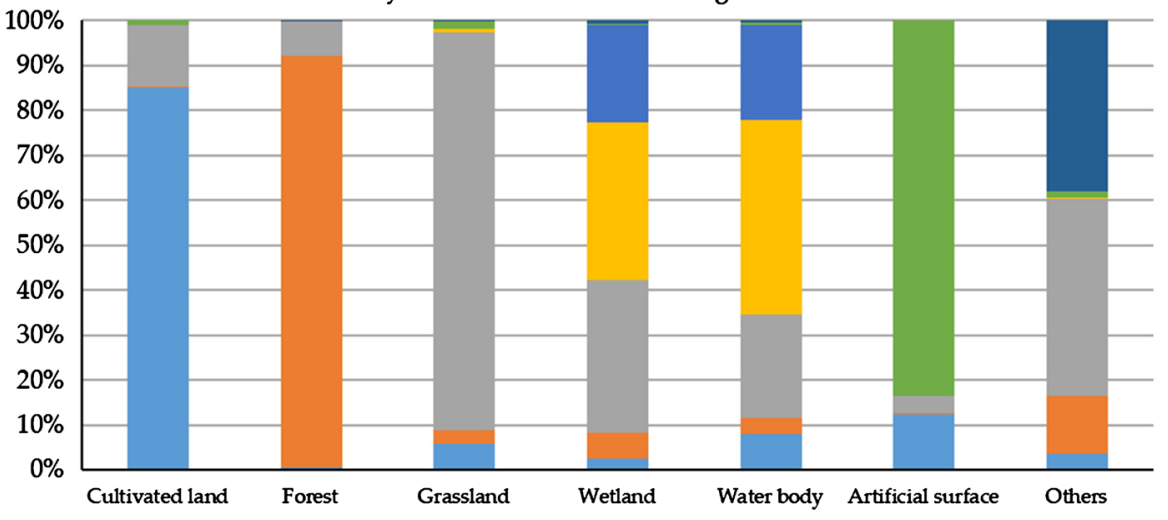

Land use transfer matrix of Water Conservation and Soil Conservation Area in (c) Mountain and Hilly Areas of Eastern Taihang Mountains from 2000 to 2010

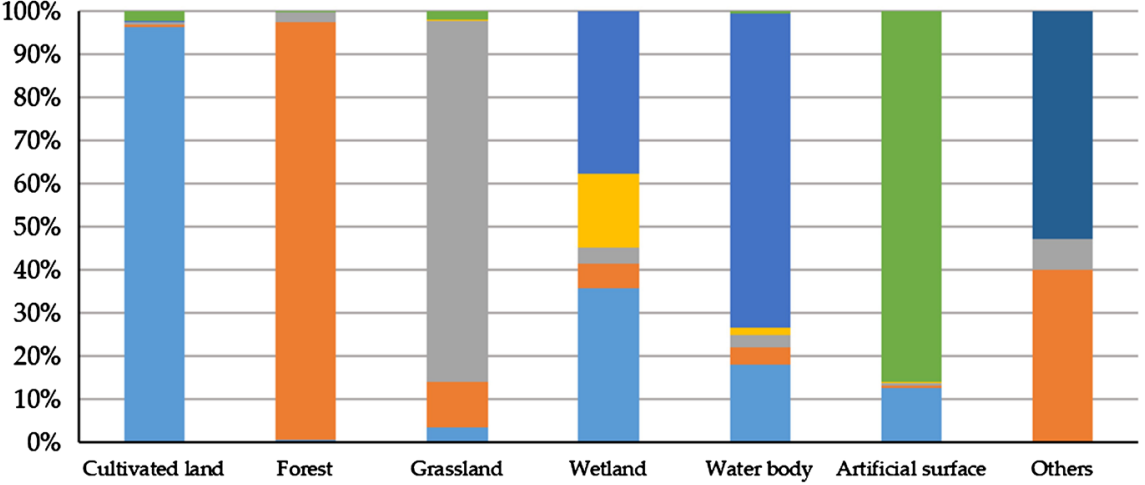

(d) Land use transfer matrix of Ecological Maintenance Zone of Bohai Bay in TianjinHebei-Shandong from 2000 to 2010

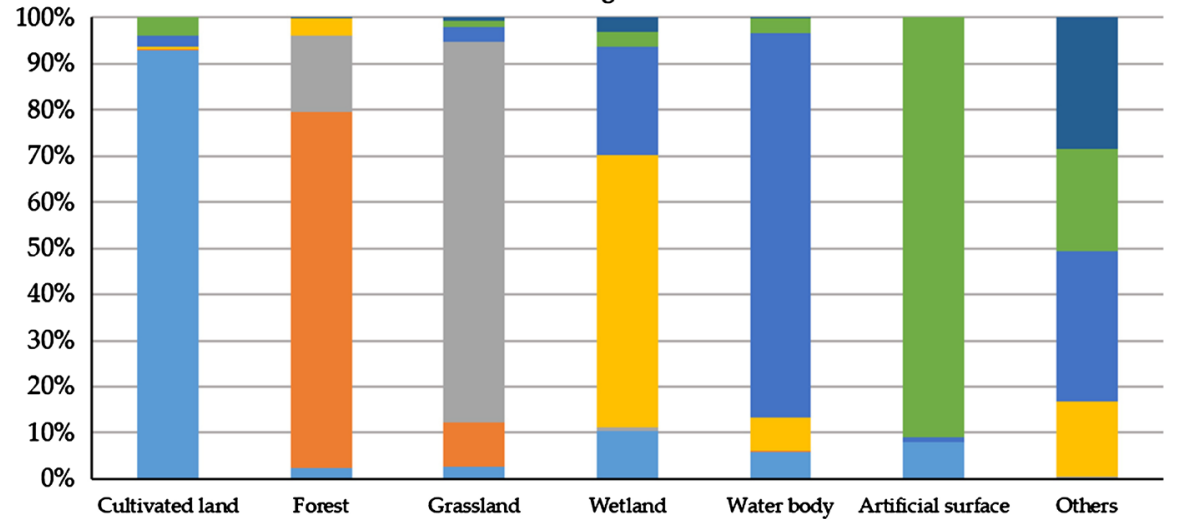


(e) Land use transfer matrix of Human Settlement Environment Maintenance and Farmland Protection Zone of Beijing-Tianjin-Hebei Urban Agglomeration from 2000 to 2010

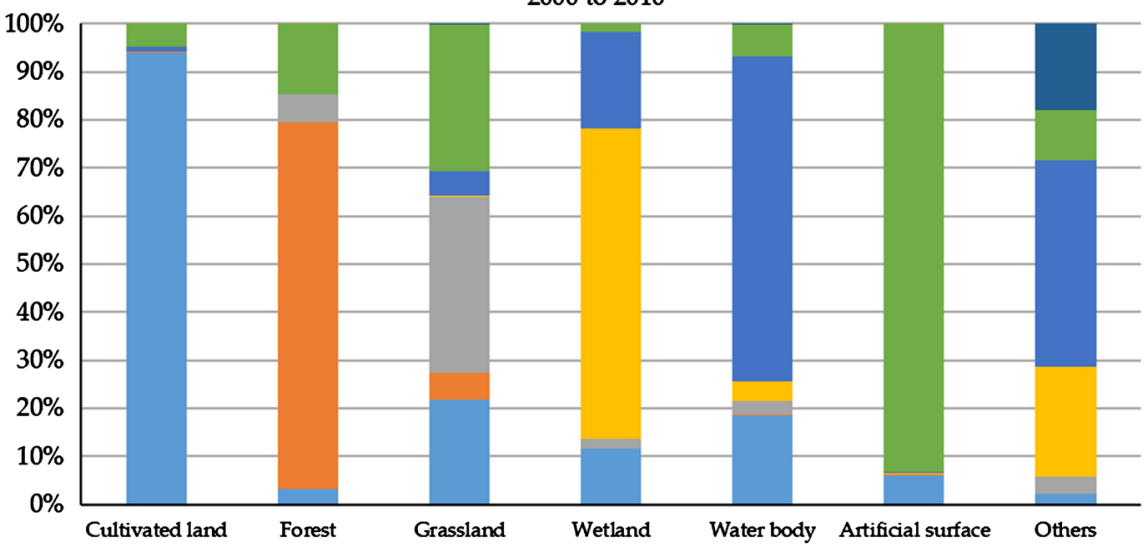

(f) Land use transfer matrix of Ecological Maintenance Area of Water Conservation in Hilly Area of Yanshan Mountain from 2000 to 2010

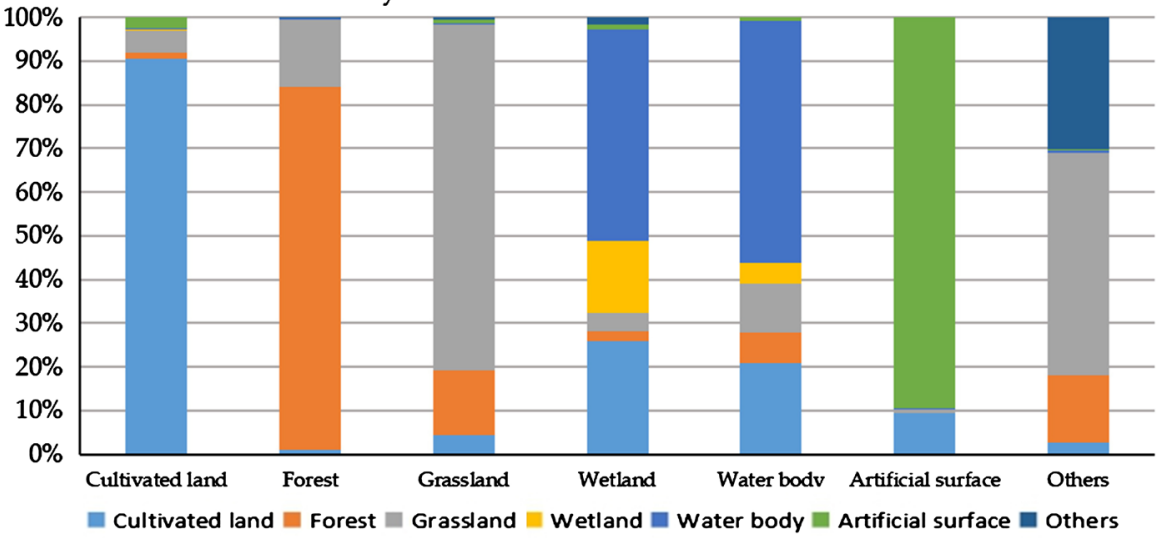

Figure 2. Transfer Matrix Graphs of Six Partition.

$1359.53 \mathrm{~km}^{2}$. Among them, the area transferred to artificial surface is 1614.91 $\mathrm{km}^{2}$, accounting for $76.23 \%$ of the total transferred out area of cultivated land. Artificial surface areas increase from $6086.80 \mathrm{~km}^{2}$ in 2000 to $7920.76 \mathrm{~km}^{2}$ in 2010 , with a total increase of $1833.96 \mathrm{~km}^{2}$.

The land use types in Ecological Maintenance Area of Water Conservation in Hilly Area of Yanshan Mountain have changed obviously except for other types. The land use types of cultivated land, forest, grassland, man-made surface and water body all changed obviously, which the changed areas are $-251.73 \mathrm{~km}^{2}$, $258.48 \mathrm{~km}^{2},-534.51 \mathrm{~km}^{2}, 584.65 \mathrm{~km}^{2},-115.98 \mathrm{~km}^{2}$, respectively.

\subsection{Landscape Index Analysis}

Through the landscape index analysis method, the landscape index bar charts of six districts of Beijing-Tianjin-Hebei were generated, as shown in Figure 3. The figure not only revealed the changes of landscape pattern index in different ecological functional areas of Beijing-Tianjin-Hebei from 2000 to 2010, but also intuitively showed the relationship between different zones of the same index. In the figure, due to space reasons, Sand Control Farmland Protection Zone in Yellow River Flood Plain, Water Conservation Area for Sand Control in Mountain and 


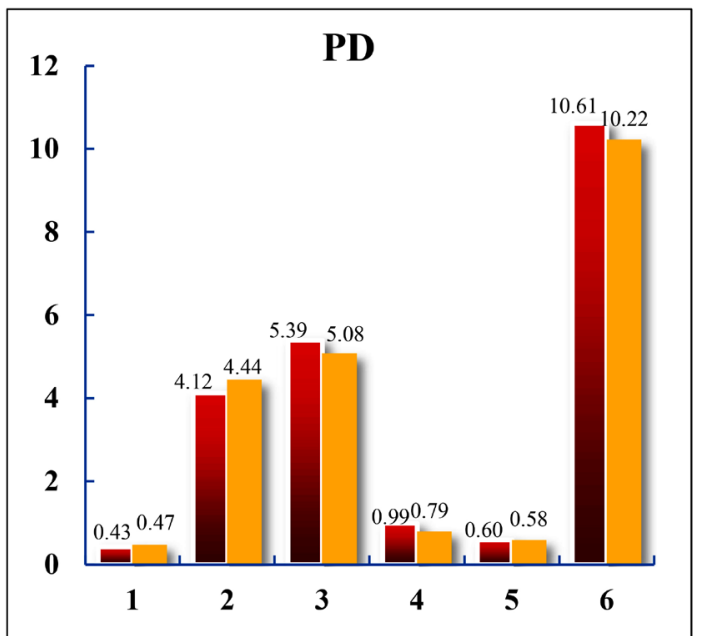

(a)

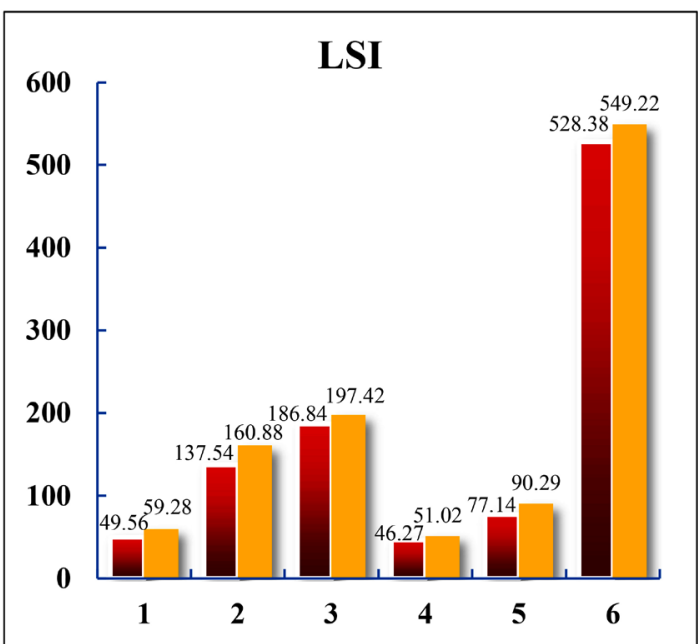

(c)

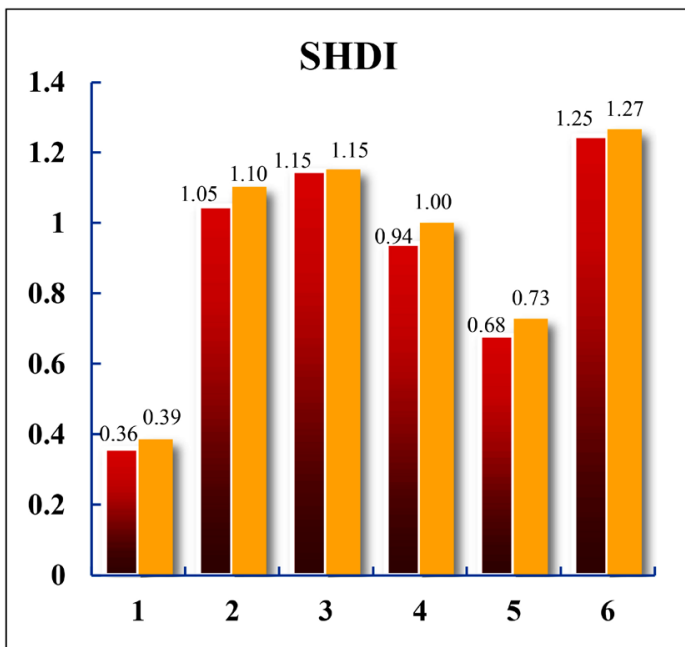

(e)

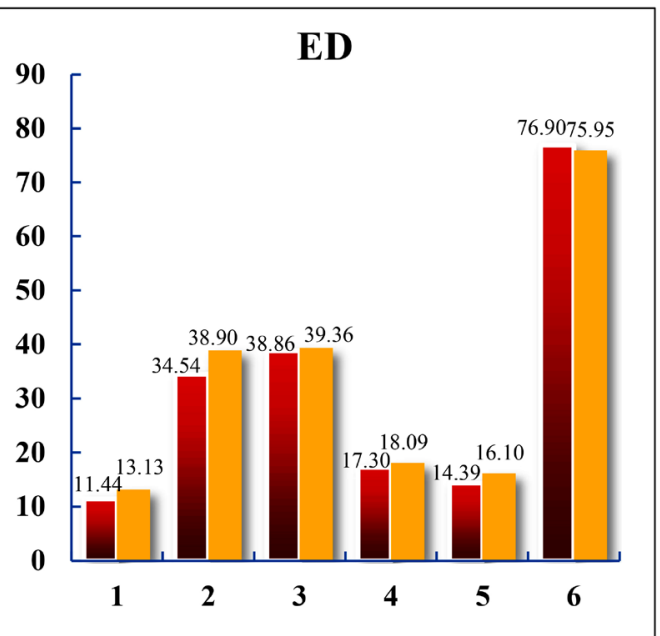

(b)

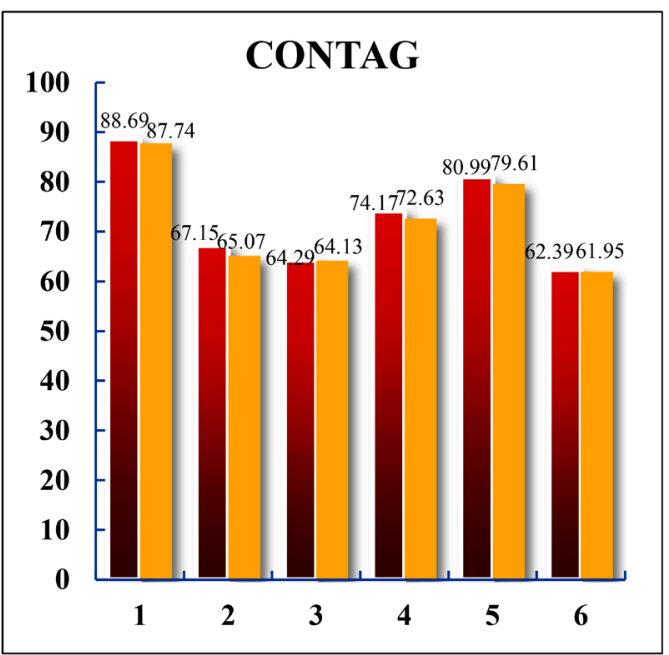

(d)

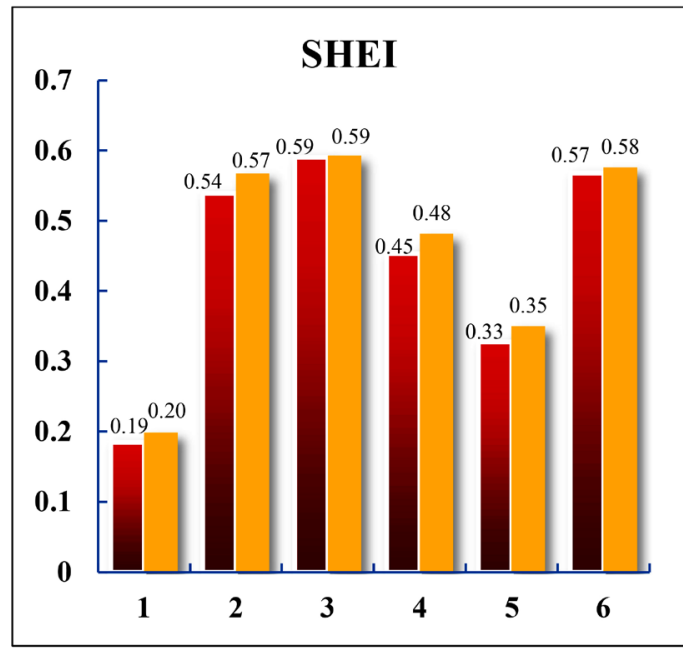

(f) $-2000=2010$

Figure 3. The line chart of landscape index change. 
Hilly Areas of Northwest Taihang Mountains, Water Conservation and Soil Conservation Area in Mountain and Hilly Areas of Eastern Taihang Mountains, Ecological Maintenance Zone of Bohai Bay in Tianjin-Hebei-Shandong, Human Settlement Environment Maintenance and Farmland Protection Zone of Beijing-Tianjin-Hebei Urban Agglomeration, Ecological Maintenance Area of Water Conservation in Hilly Area of Yanshan Mountain, which are included in broken line maps, are set as numbers 1,2, 3, 4, 5 and 6 respectively. From the Figure 3, we can see that:

The PD values of Sand Control Farmland Protection Zone in Yellow River Flood Plain, Human Settlement Environment Maintenance and Farmland Protection Zone of Beijing-Tianjin-Hebei Urban Agglomeration and Ecological Maintenance Area of Water Conservation in Hilly Area of Yanshan Mountain increase, indicating that the degree of fragmentation of the three areas is gradually increasing. At the same time, the area of artificial surface in these three areas has increased considerably. Therefore, it may be due to the strengthening of urbanization activities, which weakens the ability of landscape to resist natural disasters, and reduces the carrying capacity of ecological environment.

The ED values of Sand Control Farmland Protection Zone in Yellow River Flood Plain, Water Conservation Area for Sand Control in Mountain and Hilly Areas of Northwest Taihang Mountains, Water Conservation and Soil Conservation Area in Mountain and Hilly Areas of Eastern Taihang Mountains, Ecological Maintenance Zone of Bohai Bay in Tianjin-Hebei-Shandong, and Human Settlement Environment Maintenance and Farmland Protection Zone of Beijing-Tianjin-Hebei Urban Agglomeration tend to increase, especially in Water Conservation Area for Sand Control in Mountain and Hilly Areas of Northwest Taihang Mountains, the ED value increased from 34.54 to 38.90. It shows that patches increase, the area is irregular and the landscape types show discontinuity.

The LSI values of six districts in Beijing-Tianjin-Hebei region tend to increase, which indicates that the shapes of the landscape patches in the whole study area are complex and irregular.

The CONTAG values in the two areas of Sand Control Farmland Protection Zone in Yellow River Flood Plain and Human Settlement Environment Maintenance and Farmland Protection Zone of Beijing-Tianjin-Hebei Urban Agglomeration are higher than those in the other four areas. It shows that the dominant patch types in the landscape of Sand Control Farmland Protection Zone in Yellow River Flood Plain and Human Settlement Environment Maintenance and Farmland Protection Zone of Beijing-Tianjin-Hebei Urban Agglomeration have formed good connectivity. It also shows that there are many small patches in the landscape of the other four areas, and the landscape is a dense pattern with many elements, and the fragmentation degree of the landscape is high. In 2000, the value of Sand Control Farmland Protection Zone in Yellow River Flood Plain is 88.70 , which is close to 100 , indicating that there are dominant patch types with high connectivity in the landscape of this area. 
The values of SDHI in six districts of Beijing-Tianjin-Hebei region tends to increase, which indicates that patch types in the study area are increasing and enriching, and the distribution of patch types in landscape is balanced. The SHDI values of Water Conservation Area for Sand Control in Mountain and Hilly Areas of Northwest Taihang Mountains, Water Conservation and Soil Conservation Area in Mountain and Hilly Areas of Eastern Taihang Mountains and Ecological Maintenance Area of Water Conservation in Hilly Area of Yanshan Mountain are higher than those of the other three areas. In 2000, the SHDI values of the three regions are 1.05, 1.15 and 1.25, respectively, which suggests that they have abundant land use types and high content of uncertain information.

The increasing of the value of SHEI of six districts in Beijing-Tianjin-Hebei region indicates that the dominance degree of the study area is decreasing. However, the SHEI value of Sand Control Farmland Protection Zone in Yellow River Flood Plain is obviously lower than that in the other five areas. In 2000, the SHEI value of Sand Control Farmland Protection Zone in Yellow River Flood Plain is only 0.19 . It shows that the landscape is dominated by one or a few dominant patches.

\section{Conclusions}

The Beijing-Tianjin-Hebei region is taken as the research area, and the study area is divided into six zones. Using the two-period data of Globeland30 of 2000 and 2010, the land use transfer status and the dynamic change of landscape pattern in Beijing-Tianjin-Hebei region from 2000 to 2010 are quantitatively analyzed by adopting the methods of land use transfer matrix and landscape index analysis and using GIS technology and FRAGSTAT software.

1) From the perspective of land use change, the land use change in Beijing-Tianjin-Hebei from 2000 to 2010 is obvious. The general trend of land use change in the whole Beijing-Tianjin-Hebei region is the decrease of the area of arable land and waterbody, and the increase of the area of forest, grassland, wetland and artificial surface. Among them, cultivated land, artificial surface and grassland are the three land use types that have changed most. From the six zones of Beijing-Tianjin-Hebei, it can be seen that the partitions with significant changes are Sand Control Farmland Protection Zone in Yellow River Flood Plain, Water Conservation Area for Sand Control in Mountain and Hilly Areas of Northwest Taihang Mountains, and Human Settlement Environment Maintenance and Farmland Protection Zone of Beijing-Tianjin-Hebei Urban Agglomeration. Generally speaking, the decrease of cultivated land area and the increase of man-made surface area in Beijing-Tianjin-Hebei region coincide with the urbanization process in Beijing-Tianjin-Hebei region.

2) From the perspective of landscape pattern change, the patch density in the southeast and northwest of Beijing-Tianjin-Hebei region increases from 2000 to 2010, indicating that the degree of fragmentation in these regions increased 
gradually; the increase of edge density indicates the increase of patches and discontinuity of landscape types in Beijing-Tianjin-Hebei area, and the increase of landscape shape index indicates that landscape patches in the study area are complex and irregular in shape; the increase of the contagion index in the southeastern part of Beijing-Tianjin-Hebei region indicates that the dominant patches in the landscape form a good connection, while the increase of Shannon diversity index and Shannon evenness index in Beijing-Tianjin-Hebei region indicates the increase of patch types and the uniform distribution of patch types in the landscape.

3) This paper focuses on the landscape pattern evaluation and analysis of the fragmentation and spatial heterogeneity of Beijing-Tianjin-Hebei region by using the landscape level index. Therefore, the next step can be evaluated by selecting the landscape components and the biodiversity of the landscape, as well as the landscape index reflecting the direction and strength of human activities. At the same time, this paper evaluates the ecological zoning of Beijing-Tianjin-Hebei region, but not through the selection of the scale of typical cities, which is the focus of the next work.

\section{Acknowledgements}

Thank the National Basic Geographic Information Center for providing data support for the completion of this article, and Natural Science Foundation of Hebei Province (D2019402067) for providing financial support for the completion of this article.

\section{Conflicts of Interest}

The authors declare no conflicts of interest regarding the publication of this paper.

\section{References}

[1] Li, X.B. (1996) International Research Trends of Land Use/Land Cover Change, the Core Area of Global Environmental Change Research. Journal of Geography, No. 6, 553-558.

[2] Chen, Y.Q. and Yang, P. (2001) New Advances in Land Use/Land Cover Change Research in the World. Economic Geography, No. 1, 95-100.

[3] Yu, X. and Yang, G. (2002) Current Situation and Problems of Land Use/Cover Change Research in China. Progress in Geographic, No. 1, 51-57.

[4] Zhang, S.W. and Tang, N.Q. (2006) Research Status and Prospects of Land Use/Cover Change (LUCC). Subtropical Agriculture Research, No. 3, 221-225.

[5] Zhang, H.J. (2011) Remote Sensing Monitoring of Land Use Change. Geospatial Information, 9, 20-23+187.

[6] Chang, S. (2010) Study on Spatial Pattern of Regional Land Use Landscape: Taking Enshi, Hubei Province as an Example. Journal of Hubei Institute for Nationalities (Natural Science Edition), 28, 463-467.

[7] Loveland, T.R., Reed, B.C., Brown, J.F., Ohlen, D.O., Zhu, Z., Yang, L., et al. (2000) 
Development of a Global Land Cover Characteristics Database and IGBP DISCover from $1 \mathrm{~km}$ AVHRR Data. International Journal of Remote Sensing, 21, 1303-1330. https://doi.org/10.1080/014311600210191

[8] Fries, R.S.D., Hansen, M., Townshend, J.R.G. and Sohlberg, R. (1998) Global Land Cover Classifications at $8 \mathrm{~km}$ Spatial Resolution: The Use of Training Data Derived from Landsat Imagery in Decision Tree Classifiers. International Journal of Remote Sensing, 19, 3141-3168. https://doi.org/10.1080/014311698214235

[9] Friedl, M.A., Sulla-Menashe, D., Tan, B., Schneider, A., Ramankutty, N., Sibley, A., et al. (2009) MODIS Collection 5 Global Land Cover: Algorithm Refinements and Characterization of New Datasets. Remote Sensing of Environment, 114, 168-182. https://doi.org/10.1016/j.rse.2009.08.016

[10] Bartholome, E. and Belward, A.S. (2005) GLC2000: A New Approach to Global Land Cover Mapping from Earth Observation Data. International Journal of Remote Sensing, 26, 1959-1977. https://doi.org/10.1080/01431160412331291297

[11] Arino, O., Gross, D., Ranera, F., Bourg, L., Leroy, M., Bicheron, P., et al. (2007) GlobCover: ESA Service for Global Land Cover from MERIS. 2007 IEEE International Geoscience and Remote Sensing Symposium, Barcelona, Spain, 23-28 July 2007, 2412-2415. https://doi.org/10.1109/IGARSS.2007.4423328

[12] Hansen, M.C., Potapov, P.V., Moore, R., Hancher, M., Turubanova, S.A., Tyukavina, A., et al. (2013) High-Resolution Global Maps of 21st-Century Forest Cover Change. Science (New York, NY), 342, 850-853.

https://doi.org/10.1126/science.1244693

[13] Li, M.S., Mao, L.J., Zhou, C.G., Vogelmann, J.E. and Zhu, Z.L. (2010) Comparing Forest Fragmentation and Its Drivers in China and the USA with Globcover v2.2. Journal of Environmental Management, 91, 2572-2580. https://doi.org/10.1016/j.jenvman.2010.07.010

[14] Fan, L.J. and Tian, G.X. (2018) Land Use and Landscape Pattern Changes in Shanghai from 1995 to 2015. Bulletin of Soil and Water Conservation, 38, 287-292+98.

[15] Wang, H., Qin, F., Zhu, Y. and Zhang, C.C. (2017) The Impact of Land Use and Landscape Pattern Evolution on Ecosystem Service Value. Acta Ecologica Sinica, 37, 1286-1296. https://doi.org/10.5846/stxb201606291295

[16] Zhang, J.G., Li, J.J., Yin, B.K., Gao, Y.F. and Liu, X.Y. (2018) Land Use Change Analysis of Zhungeer Banner Based on Transfer Matrix. Bulletin of Soil and Water Conservation, 38, 131-134.

[17] Lamine, S., Petropoulos, G.P., Singh, S.K., Szabó, S., Bachari, N.E.I., Srivastava, P.K., et al. (2018) Quantifying Land Use/Land Cover Spatio-Temporal Landscape Pattern Dynamics from Hyperion Using SVMs Classifier and FRAGSTATS ${ }^{\circledR}$. Geocarto International, 33, 862-878. https://doi.org/10.1080/10106049.2017.1307460

[18] Chen, J., Chen, J., Liao, A.P., Cao, X., Chen, L.J., Chen, X.H., et al. (2014) Overall Technology of Remote Sensing Mapping for Global $30 \mathrm{~m}$ Surface Coverage. Acta Geodaetica et Cartographica Sinica, 43, 551-557.

[19] Chen, J., Chen, J. and Liao, A.P. (2016) Remote Sensing Mapping of Global Land Cover. Science Press, Beijing.

[20] Zhao, G. (2018) Research on Precision Evaluation Method of Remote Sensing Products for Surface Coverage. Beijing University of Architecture, Beijing.

[21] Ma, J.Z., Sun, Q., Xiao, Q. and Wen, B.W. (2016) Accuracy Assessment and Contrastive Analysis of GlobeLand30 Data in Henan Province. Journal of Geo-Information Science, 18, 1563-1572. 
[22] Chen, J. (2018) Study on the Change Of Global Cultivated Land Use Pattern Based on GlobeLand30. Scientia Agricultura Sinica, 51, 1089-1090.

[23] Chang, Y.S., Chen, J., Chen, L.J., Li, R., Zhang, W.W., Lu, N., et al. (2015) Characteristics of Siberian Land Cover Change from 2000 to 2010: Based on the Analysis of GlobeLand30. Progress in Geographic, 34, 1324-1333.

[24] Sang, H.Y., Li, S., Wei, Y.Z. and Zhai, L. (2019) Monitoring and Analysis of Temporal and Spatial Distribution of PM2.5/PM10 Concentration in Beijing-Tianjin-Hebei Region. Science of Surveying and Mapping, 44, 317-323.

[25] China, M.O.W.R.O.T.P.R.O. (2012) Circular on the Issuance of "National Soil and Water Conservation Zoning (Trial Implementation)" (Running Water and Soil Conservation [2012] 512). In: China MoWRotPRo, editor.

[26] Fu, G.Z. and Ling, F. (2016) Discussion on Soil and Water Conservation Based on the Coordinated Development of Beijing-Tianjin-Hebei. Soil and Water Conservation in China, No. 1, 20-23.

[27] Chen, J., Ban, Y.F. and Li, S.N. (2014) Open Access to Earth Land-Cover Map. Nature, 514, 434. https://doi.org/10.1038/514434c

[28] Chen, J., Chen, J., Liao, A.P., Cao, X., Chen, L.J., Chen, X.H., et al. (2015) Global land Cover Mapping at $30 \mathrm{~m}$ Resolution: A POK-Based Operational Approach. ISPRS Journal of Photogrammetry and Remote Sensing, 103, 7-27. https://doi.org/10.1016/j.isprsjprs.2014.09.002

[29] Xu, L. and Zhao, Y. (1993) Forecasting Land Use Pattern Change in Dongling District by Markov Process. Chinese Journal of Applied Ecology, No. 3, 272-277.

[30] Zhu, H.Y. and Li, X.B. (2003) Discussion on the Model Method of Regional land Use Change Index. Acta Geographica Sinica, No. 5, 643-650. https://doi.org/10.1016/B978-0-7506-7444-7/50072-8

[31] Wu, J.G. (2000) Landscape Ecology-Patterns, Processes, Scales and Grades. Higher Education Press, Beijing.

[32] Zhang, H.Y., Fan, J.W. and Qin, S.Q. (2015) Land Use/Cover Change in the Project Area of Returning Grazing Land to Grassland in China from 2000 to 2010. Progress in Geography, 34, 840-853.

[33] Wang, Y.F., Shen, Y.M., Chen, S.J. and Wu, D.L. (2012) The Range Effect of Landscape Pattern Index Correlation. Chinese Journal of Ecology, 31, 2091-2097.

[34] Hazia, B., Wu, Z.P., Chen, X.G. and Hursibek, Z. (2018) Analysis of Landscape Pattern Change and Driving Force in Urumqi. Ecological Science, 37, 62-70. 